\title{
MicroscopyPioneers
}

\section{Pioneers in Optics: Thomas Young}

\section{Eric Clark}

From the website Molecular Expressions created by the late Michael Davidson and now maintained by Eric Clark, National Magnetic Field Laboratory, Florida State University, Tallahassee, FL 32306

eclark@magnet.fsu.edu

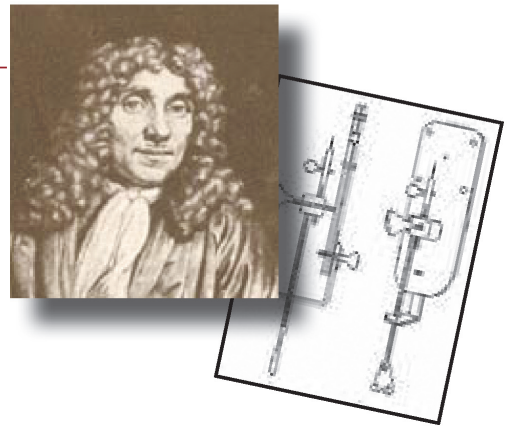

\section{Thomas Young}

(1773-1829).

Thomas Young's epitaph in Westminster Abbey states that he was "...a man alike eminent in almost every department of human learning."

Young was an English physician and a physicist who was responsible for many important theories and discoveries in optics and in human anatomy.

In 1799 Young initiated his medical practice in London. His primary interest was in studying sensory perception and, while still in medical school, discovered

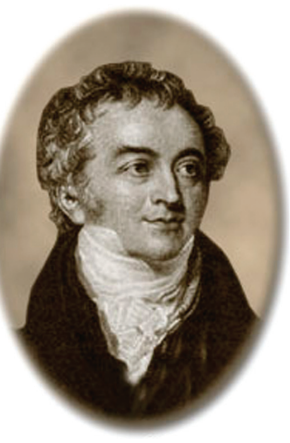
how the lens of the human eye changes shape to focus on objects at different distances. While pursuing his interests in the function of the human eye, Young discovered the cause of astigmatism in 1801, which was about the time that he began his study of light.

In 1801, Young began a series of experiments that addressed a phenomenon known as interference. He observed that when light from a single source is separated into two beams and the two beams are recombined, the combined beams produce a pattern of light and dark fringes. Young concluded that these fringes were the result of the beams of light behaving as waves with their peaks and troughs either reinforcing one another or canceling each other. When this occurred, alternating lines of light and dark resulted.

Young applied his new wave theory of light to explain the colors of thin films such as soap bubbles, and by relating color to wavelength, he calculated the approximate wavelengths of the seven colors recognized by Newton. His proposal of this wave theory of light was not accepted by most English scientists of the period because it opposed Newton's theory of light. It was not until Young worked with French physicists Augustin Fresnel and Francois Arago that his wave theory began to be accepted in Europe.

Young was also responsible for postulating how the receptors in the eye perceive colors. He is credited, along with Hermann Ludwig Ferdinand von Helmholtz, for developing the Young-Helmholtz trichromatic theory. This theory postulated that there were three distinct types of cones in the retina and that each one of the types was sensitive to a particular color: red, green, or blue. They also speculated that when a color stimulus was captured by the eye it was the cone receptor structures that received and transmitted that information to the brain.
As indicated by his epitaph, Young's interests and mastery of scientific and medical skills was quite varied. He was fluent in several languages and studied Egyptology. He also began studying the texts of the Rosetta Stone in 1814. After obtaining additional hieroglyphic writings from other sources, he succeeded in providing a relatively accurate translation and contributed to the deciphering of the ancient Egyptian language.

Young also did experiments concerned with measuring the size of molecules, surface tension in liquids, and quantities of elasticity. Additionally, he was the first scientist to give the word "energy" its scientific connotation. Young's modulus, a constant in the mathematical equation describing elasticity, was named in his honor.

\section{WHAT DOES YOUR SEM 'SEE'?}

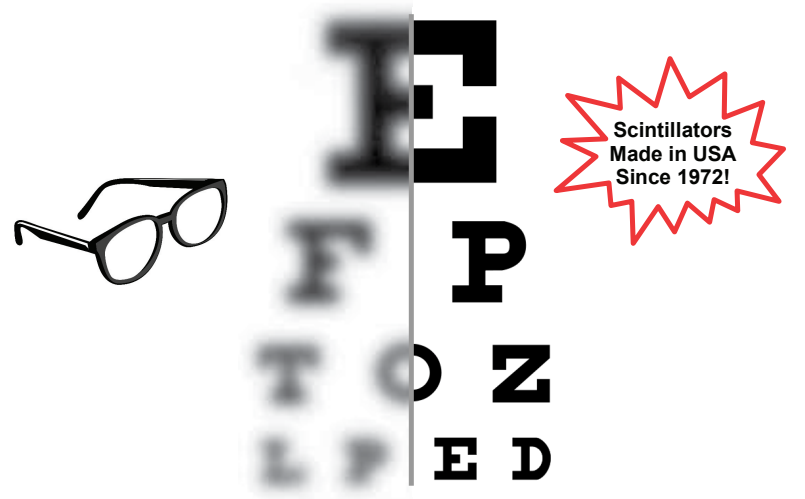

BUY A NEW SCINTILLATOR!

$\checkmark$ Common sizes in stock $\checkmark$ Easy To Install! $\checkmark$ Prices from $\$ 99$

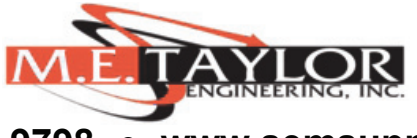

(301) 975-9798 • www.semsupplies.com 


\section{June $3-8$,}

\section{8}

\section{LEHIGH}

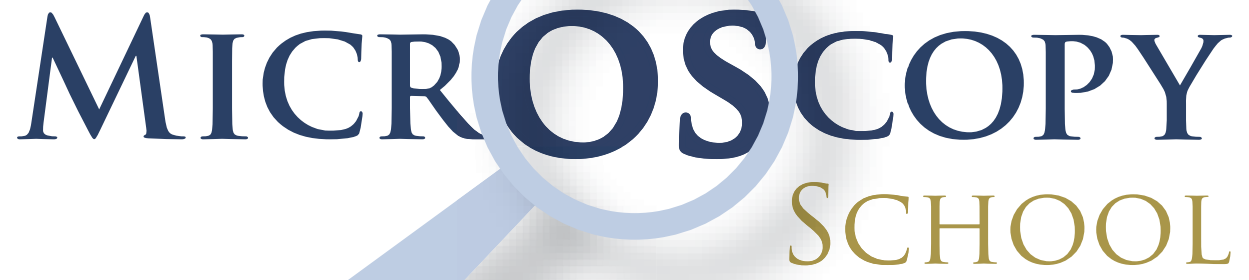

Lehigh University, Bethlehem, PA USA

\section{MAIN COURSES}

SCANNING ELECTRON MICROSCOPY AND X-RAY MICROANALYSIS

June 4-8

\section{SPECIALIZED COURSES}

FOCUSED ION BEAM (FIB):

Instrumentation and Applications

June 4-8

PROBLEM SOLVING:

Interpretation and Analysis

of SEM/EDS/EBSD Data

June 4-8
INTRODUCTION TO SEM AND EDS FOR THE NEW OPERATOR June 3

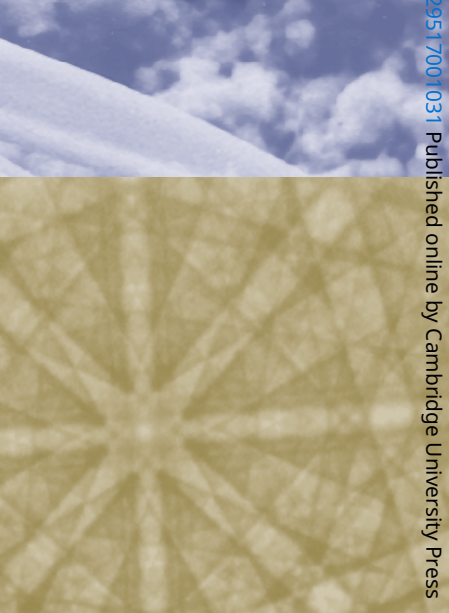

